\title{
APLICAÇÃO DA METODOLOGIA DE PLANEJAMENTO FATORIAL E ANÁLISE DE SUPERFÍCIES DE RESPOSTA PARA AVALIAÇÃO DO CRESCIMENTO DO CLOSTRIDIUM ACETOBUTYLICUM ATCC 4259 UTILIZANDO GLICEROL P.A. COMO SUBSTRATO
}

\author{
C. E. de O. LACERDA $^{1}$, G. M. VINHAS ${ }^{1}$, Y. M. B. de ALMEIDA ${ }^{1}$ \\ ${ }^{1}$ Universidade Federal de Pernambuco, Departamento de Engenharia Química \\ E-mail para contato: carlos.olacerda@hotmail.com
}

\begin{abstract}
RESUMO - A glicerina, subproduto da produção de biodiesel, vem sendo investigada como fonte de carbono em processos microbianos para a obtenção de bioprodutos com alto valor agregado. A avaliação do crescimento do microorganismo responsável por essa bioconversão é uma importante etapa desse processo. O presente trabalho consistiu em avaliar o comportamento do Clostridium acetobutylicum ATCC 4259 através de fermentações em batelada utilizando glicerol P.A. como fonte de carbono. Foi realizado um planejamento fatorial $2^{2} \mathrm{em}$ estrela com ponto central para avaliar a influência do glicerol P.A. e do extrato de levedura sobre o crescimento do micro-organismo. A técnica de peso seco foi utilizada para o cálculo da concentração do micro-organismo presente em cada cultura após a fermentação. As melhores respostas do planejamento fatorial foram obtidas utilizando $30 \mathrm{~g} / \mathrm{L}$ de glicerol e $2 \mathrm{~g} / \mathrm{L}$ de extrato de levedura no meio de cultura, sendo elas $1,42 \mathrm{~g} / \mathrm{L}$ e $1,40 \mathrm{~g} / \mathrm{L}$ de biomassa.
\end{abstract}

\section{INTRODUÇÃO}

O uso contínuo de combustíveis fósseis tem causado graves consequências ao meio ambiente. Uma das alternativas mais prementes para minimizar esses problemas são os biocombustíveis, que tem características similares, permitindo que eles sejam utilizados em sistemas de combustão. Por serem de origem vegetal, eles contribuem para o ciclo do carbono na atmosfera e por isso são considerados renováveis. O Brasil é um dos pioneiros no uso deste tipo de combustível já utilizando o álcool etílico, oriundo da fermentação da cana de açúcar, desde a década de 1970 (Mota et al., 2009; Pinto, 2009).

O biodiesel é um combustível renovável, biodegradável e não tóxico. Pode ser definido como sendo um mono-alquil éster de ácidos graxos derivados de fontes renováveis (óleos vegetais e gordura animal) com álcool na presença de um catalisador, obtido através de um processo de transesterificação, no qual ocorre a transformação de triglicerídeos em moléculas menores de ésteres de ácidos graxos e tendo como subproduto principal, a glicerina (glicerol mais impurezas) (Fukuda et al., 2009; Leoneti et al., 2012).

Nos primeiros anos de produção do biodiesel, a alta percentagem de glicerina obtida era considerada como um aspecto positivo, e com sua venda, o aumento da competitividade 
econômica global da fabricação de biodiesel parecia seguro, uma vez que a glicerina gerada na produção corresponde aproximadamente $10 \%$ do volume total de biodiesel produzido (Yazdani \& Gonzalez, 2007). Em 2010, a produção de biodiesel no Brasil foi de aproximadamente 2,4 bilhões de litros, o que gerou aproximadamente 240 milhões de litros de glicerina (Leoneti et al., 2012).

O acúmulo da oferta ocasionado pelo crescimento das indústrias de biocombustíveis e a quantidade de impurezas encontradas na glicerina bruta, fizeram com que seu preço diminuísse com o passar dos anos (Yazdani \& Gonzalez, 2007; Asad-Ur-Rehman et al., 2008). Desta forma, essa glicerina oriunda da produção de biodiesel passou de um produto apreciado a um problema de eliminação de resíduo, e existe um grande interesse em sua purificação ou no seu reaproveitamento direto sem tratamento, proporcionando ao processo de produção de biodiesel maior competitividade e valorização crescente no mercado de biocombustíveis (Kaur et al., 2012; Clomburg et al., 2013).

Sendo assim, a glicerina bruta não purificada ou com purificação parcial vem sendo investigada como fonte de carbono em processos microbianos para obtenção de bioprodutos de alto valor agregado como 1,3-propanodiol, etanol, butanol, acetona, ácido acético, ácido butírico, ácido cítrico, ácido fórmico, ácido lático, ácido succínico, $\mathrm{CO}_{2} \mathrm{e} \mathrm{H}_{2}$. (Anand et al., 2011; Clomburg et al., 2013).

A avaliação do crescimento do micro-organismo responsável por essa bioconversão é uma importante etapa para compreender todo o mecanismo e otimizar o aproveitamento da glicerina residual. A formação de biomassa no processo fermentativo depende de duas moléculas transportadoras de energia, o $\mathrm{NAD}^{+}$(dinucleotídeo de adenina nicotinamida) e o ATP (adenosina trifosfato) (Kaur et al., 2012).

O objetivo do presente trabalho foi utilizar o glicerol P.A. como fonte de carbono no processo de fermentação em batelada simples do Clostridium acetobutylicum ATCC 4259, e avaliar a influencia desse glicerol P.A. e do extrato de levedura no seu crescimento, através de um planejamento fatorial $2^{2}$ em estrela com ponto central.

\section{MATERIAIS E MÉTODOS}

\subsection{Materiais}

Micro-organismo: O micro-organismo utilizado no trabalho foi o Clostridium acetobutylicum ATCC 4259. Essa linhagem foi cedida pela coleção de micro-organismos UFPEDA do Departamento de Antibióticos da UFPE. Foi adquirida em tubos contendo meio RCM (Caldo Clostridial Reforçado) semissólido, e foi mantida em estufa a $37{ }^{\circ} \mathrm{C}$ até ser inoculada e/ou repicada.

Soluções Utilizadas: Meio de tioglicolato fluido (marca DIFCO), utilizado para manutenção e crescimento do micro-organismo e solução salina para diluição (Tabela 1). 
Tabela 1 - Composição da solução salina para diluição

\begin{tabular}{cc}
\hline \multicolumn{2}{c}{ Solução A } \\
\hline $\mathrm{KH}_{2} \mathrm{PO}_{4}$ & $34,0 \mathrm{~g}$ \\
Água destilada & $1000,0 \mathrm{~mL}$ \\
\hline \multicolumn{2}{c}{ Solução B } \\
\hline $\mathrm{MgSO}_{4} \cdot 7 \mathrm{H}_{2} \mathrm{O}$ & $50,0 \mathrm{~g}$ \\
Água destilada & $1000,0 \mathrm{~mL}$ \\
\hline \multicolumn{2}{c}{ Solução Salina } \\
\hline Solução A & $1,25 \mathrm{~mL}$ \\
Solução B & $5,0 \mathrm{~mL}$ \\
Água destilada & $1000,0 \mathrm{~mL}$ \\
\hline
\end{tabular}

A pré-cultura utilizada para adaptar o micro-organismo ao meio de cultura para fermentação tem a seguinte composição (Günzel et al., 1991): $\mathrm{K}_{2} \mathrm{HPO}_{4}(3,4 \mathrm{~g} / \mathrm{L}), \mathrm{KH}_{2} \mathrm{PO}_{4}$ $(1,3 \mathrm{~g} / \mathrm{L}),\left(\mathrm{NH}_{4}\right)_{2} \mathrm{SO}_{4}(2,0 \mathrm{~g} / \mathrm{L}), \mathrm{MgSO}_{4} \cdot 7 \mathrm{H}_{2} \mathrm{O}(0,2 \mathrm{~g} / \mathrm{L}), \mathrm{CaCl}_{2} \cdot 2 \mathrm{H}_{2} \mathrm{O}(0,02 \mathrm{~g} / \mathrm{L}), \mathrm{CaCO}_{3}(2,0$ $\mathrm{g} / \mathrm{L})$, extrato de levedura $(1,0 \mathrm{~g} / \mathrm{L})$, glicerol P.A. (20 g/L), solução de elementos traços $(1,0$ $\mathrm{mL} / \mathrm{L})$ (Tabela 2) e solução de ferro $(2,0 \mathrm{~mL} / \mathrm{L})$ (Tabela 3$)$.

Tabela 2 - Composição da solução de elementos traços

\begin{tabular}{cc}
\hline \multicolumn{3}{c}{ Componentes } \\
\hline $\mathrm{ZnCl}_{2}$ & $0,070 \mathrm{~g} / \mathrm{L}$ \\
$\mathrm{MnCl}_{2} \cdot 4 \mathrm{H}_{2} \mathrm{O}$ & $0,100 \mathrm{~g} / \mathrm{L}$ \\
$\mathrm{H}_{3} \mathrm{BO}_{3}$ & $0,060 \mathrm{~g} / \mathrm{L}$ \\
$\mathrm{CoCl}_{2} \cdot 6 \mathrm{H}_{2} \mathrm{O}$ & $0,200 \mathrm{~g} / \mathrm{L}$ \\
$\mathrm{CuCl}_{2} \cdot 2 \mathrm{H}_{2} \mathrm{O}$ & $0,020 \mathrm{~g} / \mathrm{L}$ \\
$\mathrm{NiCl}_{2} \cdot 6 \mathrm{H}_{2} \mathrm{O}$ & $0,025 \mathrm{~g} / \mathrm{L}$ \\
$\mathrm{Na}_{2} \mathrm{MoO}_{4} \cdot \mathrm{H}_{2} \mathrm{O}$ & $0,035 \mathrm{~g} / \mathrm{L}$ \\
$\mathrm{HCl} 37 \%$ & $0,900 \mathrm{~mL} / \mathrm{L}$ \\
\hline
\end{tabular}

Tabela 3 - Composição da solução de Ferro

\begin{tabular}{cc}
\hline \multicolumn{2}{c}{ Componentes } \\
\hline $\mathrm{FeSO}_{4} .7 \mathrm{H}_{2} \mathrm{O}$ & $5,0 \mathrm{~g} / \mathrm{L}$ \\
$\mathrm{HCl} 37 \%$ & $4,0 \mathrm{~mL} / \mathrm{L}$ \\
\hline
\end{tabular}


A concentração dos nutrientes do meio de cultura para fermentação é igual à concentração dos nutrientes da pré-cultura, com exceção de: $\mathrm{K}_{2} \mathrm{HPO}_{4}(1,0 \mathrm{~g} / \mathrm{L}), \mathrm{KH}_{2} \mathrm{PO}_{4}(0,5$ $\mathrm{g} / \mathrm{L}),\left(\mathrm{NH}_{4}\right)_{2} \mathrm{SO}_{4}(1,0 \mathrm{~g} / \mathrm{L})$ e solução de ferro $(1,0 \mathrm{~mL} / \mathrm{L})$, além do extrato de levedura e do glicerol P.A., que tem suas concentrações variando de acordo com os níveis do planejamento fatorial.

\subsection{Metodologia Experimental}

Planejamento fatorial: Foi realizado um planejamento fatorial $2^{2}$ estrela com ponto central. As variáveis independentes foram o glicerol P.A. e o extrato de levedura e a variável dependente foi o crescimento celular. O glicerol é a fonte principal de carbono do microorganismo, e o extrato de levedura além de fonte secundária de carbono, é também uma fonte de vitaminas. Os níveis codificados e descodificados encontram-se na Tabela 4 e os ensaios executados no planejamento encontram-se na Tabela 5.

Tabela 4 - Variáveis e níveis do planejamento experimental $2^{2}$ em estrela com ponto central

\begin{tabular}{cccccc}
\hline \multirow{2}{*}{ Variáveis Independentes } & $-\sqrt{\mathbf{2}}$ & -1 & 0 & +1 & $\sqrt{\mathbf{2}}$ \\
\hline Glicerol P.A. $(\mathrm{g} / \mathrm{L})$ & 15,86 & 20 & 30 & 40 & 44,14 \\
Extrato de Levedura $(\mathrm{g} / \mathrm{L})$ & 0,59 & 1,0 & 2,0 & 3,0 & 3,41 \\
\hline
\end{tabular}

Tabela 5 - Ensaios do planejamento experimental $2^{2}$ em estrela com ponto central

\begin{tabular}{ccc}
\hline Ensaio & $\begin{array}{c}\text { Glicerol } \\
\text { P.A. }\end{array}$ & $\begin{array}{c}\text { Extrato de } \\
\text { Levedura }\end{array}$ \\
\hline 1 & - & - \\
2 & + & - \\
3 & - & + \\
4 & + & + \\
5 & $-\sqrt{2}$ & 0 \\
6 & $\sqrt{2}$ & 0 \\
7 & 0 & $-\sqrt{2}$ \\
8 & 0 & $\sqrt{2}$ \\
9 & 0 & 0 \\
10 & 0 & 0 \\
\hline
\end{tabular}

Preparação dos meios de cultura: Os meios de cultura foram preparados de acordo com as seguintes etapas: os nutrientes de cada meio foram pesados e diluídos em água destilada; após diluição, foram insuflados com gás nitrogênio e aquecidos a $\mathrm{T}=55^{\circ} \mathrm{C}$ durante 20 minutos; os meios de cultura então foram transferidos para tubos de penicilina, selados e lacrados; os tubos seguiram para a esterilização em autoclave, a $121^{\circ} \mathrm{C}$ por 15 minutos.

Preparo da fermentação: Utilizando uma seringa (c/ agulha) estéril, o C. acetobutylicum ATCC 4259 foi inoculado em um tubo de penicilina de $100 \mathrm{~mL}$ contendo $90 \mathrm{~mL}$ de meio de tioglicolato fluido na proporção de $10 \% \mathrm{v} / \mathrm{v}$ e incubado a $35{ }^{\circ} \mathrm{C}$. Após 24 horas de 
crescimento o micro-organismo foi inoculado, também na proporção de $10 \% \mathrm{v} / \mathrm{v}$, em outro tubo de penicilina de $100 \mathrm{~mL}$ contendo $90 \mathrm{~mL}$ de pré-cultura. Após $24 \mathrm{~h}$ na incubadora a 35 ${ }^{\circ} \mathrm{C}$, foi feita a inoculação $(10 \% \mathrm{v} / \mathrm{v}) \mathrm{em} \mathrm{dez}$ tubos de penicilina de $10 \mathrm{~mL}$, cada um com $9 \mathrm{~mL}$ de meio de cultura correspondendo aos dez ensaios do planejamento fatorial. Os dez tubos de penicilina seguiram para a incubadora a $\mathrm{T}=35{ }^{\circ} \mathrm{C}$ durante $72 \mathrm{~h}$, tempo que durou a fermentação.

Avaliação da biomassa: Para avaliar o crescimento do micro-organismo foi utilizada a técnica do peso seco. Ao término das $72 \mathrm{~h}$ de fermentação, as dez amostras foram filtradas com o auxílio de um conjunto para filtração em membranas de $2 \mu \mathrm{m}$ previamente taradas, utilizando água de diluição (Tabela 1) para lavagem. As membranas permaneceram 2 horas na estufa a $\mathrm{T}=80^{\circ} \mathrm{C}$ para secar o filtrado. A diferença entre o peso inicial da membrana e o peso após a secagem determina a biomassa que cresceu durante a fermentação.

\section{RESULTADOS E DISCUSSÃO}

\subsection{Crescimento do micro-organismo}

Através da metodologia apresentada, o crescimento do micro-organismo foi quantificado nos dez ensaios do planejamento fatorial após as 72 horas de fermentação. Os resultados podem ser vistos na Tabela 6 .

Tabela 6 - Resultados do crescimento do Clostridium acetobutylicum ATCC 4259 ao final das 72 horas de fermentação

\begin{tabular}{cccc}
\hline Ensaio & $\begin{array}{c}\text { Concentração } \\
\text { Celular }(\mathrm{g} / \mathrm{L})\end{array}$ & Ensaio & $\begin{array}{c}\text { Concentração } \\
\text { Celular }(\mathrm{g} / \mathrm{L})\end{array}$ \\
\hline 1 & 1,00 & 6 & 0,74 \\
2 & 0,76 & 7 & 0,91 \\
3 & 0,85 & 8 & 1,16 \\
4 & 0,26 & 9 & 1,42 \\
5 & 0,59 & 10 & 1,40 \\
\hline
\end{tabular}

Através dos resultados da Tabela 6 , foi observado que os ensaios que apresentaram melhores respostas foram os ensaios 9 e 10 , ou seja, $30 \mathrm{~g} / \mathrm{L}$ de glicerol P.A. e $2 \mathrm{~g} / \mathrm{L}$ de extrato de levedura. Este fato está de acordo com os estudos encontrados na literatura, que apontam concentrações menos elevadas de glicerol como sendo ótimas em processos de batelada (Ringel et al., 2012).

São raros os trabalhos na literatura que quantificam o crescimento microbiano do $C$. acetobutylicum ATCC 4259 utilizando glicerol P.A. como fonte principal de carbono. Ferreira et al. (2012) executaram a fermentação do C. acetobutylicum ATCC 4259 para produção de 1,3-propanodiol na ausência de extrato de levedura e em três concentrações diferentes de glicerol P.A. no meio de cultura: 10, 30 e $60 \mathrm{~g} / \mathrm{L}$. A fermentação foi conduzida em frascos de penicilina de $100 \mathrm{~mL}$, sem controle de $\mathrm{pH}$ a uma temperatura de $35^{\circ} \mathrm{C}$ durante 72 horas. Para $10 \mathrm{~g} / \mathrm{L}$ de glicerol, uma biomassa final de $1,04 \mathrm{~g} / \mathrm{L}$ foi alcançada; para $30 \mathrm{~g} / \mathrm{L}$ de glicerol, uma 
biomassa final de $1,24 \mathrm{~g} / \mathrm{L}$ foi alcançada; e para $60 \mathrm{~g} / \mathrm{L}$ de glicerol, uma biomassa final de $1,34 \mathrm{~g} / \mathrm{L}$ foi alcançada. Pode-se concluir que a diferença entre os experimentos é causada principalmente pela presença de extrato de levedura, comprovando assim sua importância como fonte de nutrientes para o micro-organismo.

\subsection{Avaliação estatística do planejamento fatorial}

O planejamento fatorial foi avaliado através do programa Statistica ${ }^{\circledR}$ (versão 7.0). $\mathrm{Na}$ Figura 1 encontra-se o gráfico de pareto. A superfície de resposta encontra-se na Figura 2 e as curvas de nível podem ser vistas na Figura 3.

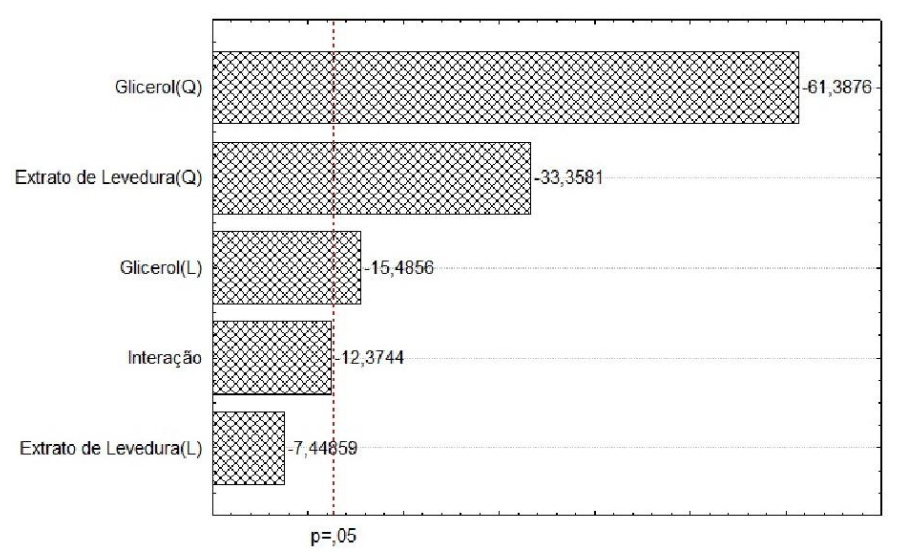

Figura 1 - Efeito das variáveis independentes sobre a concentração celular. (Q) representa o termo quadrático e $(\mathrm{L})$ representa o termo linear

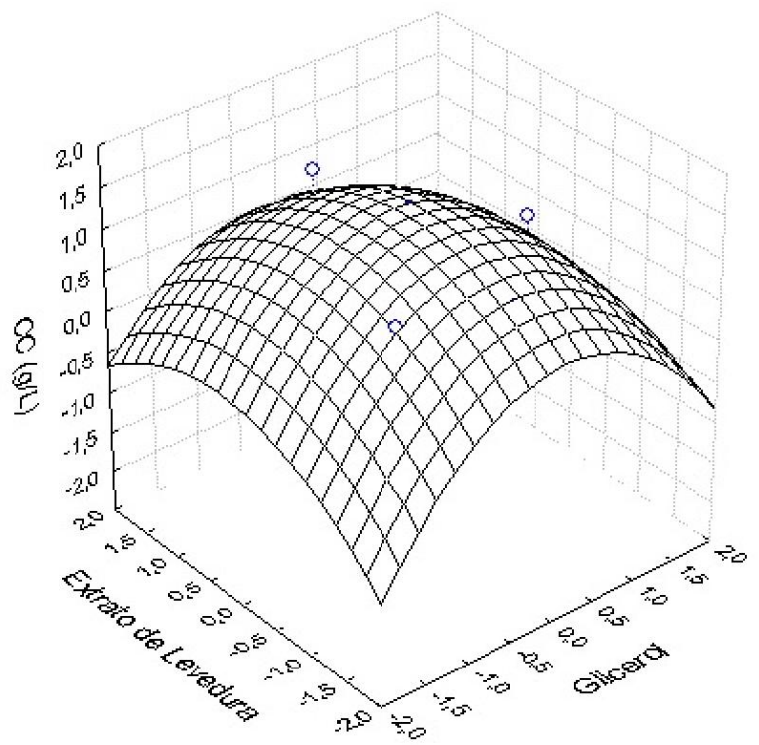

Figura 2 - Efeitos do glicerol e do extrato de levedura no crescimento do micro-organismo 


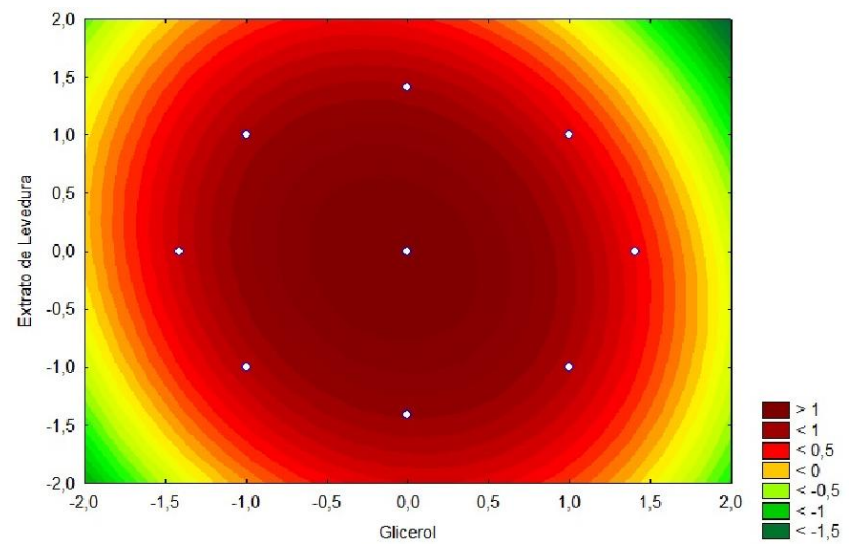

Figura 3 - Curvas de nível da concentração celular em função do glicerol e do extrato de levedura

Analisando a Figura 1, observam-se os efeitos estatisticamente significantes num nível de $95 \%$ de confiança para o crescimento do Clostridium acetobutylicum ATCC 4259. São eles: o termo quadrático do glicerol e do extrato de levedura, além do termo linear do glicerol. Observa-se que esses efeitos são negativos, fato verificado na Figura 2 pela concavidade da superfície de resposta voltada para baixo.

A Figura 1 mostra também que o efeito do glicerol é maior que o efeito do extrato de levedura, comprovando assim que o glicerol atua como fonte principal de carbono para o micro-organismo. Mesmo não sendo a fonte principal, o extrato de levedura mostrou-se necessário como fonte secundária de carbono, e fonte de outros estimulantes para as reações enzimáticas de crescimento do Clostridium acetobutylicum ATCC 4259.

Através da Figura 3 verifica-se que a concentração máxima de crescimento celular do Clostridium acetobutylicum ATCC 4259 no experimento é obtida quando a concentração do glicerol no meio de cultura está entre 25 e $35 \mathrm{~g} / \mathrm{L}$ e a concentração do extrato de levedura entre 1,5 e $2,5 \mathrm{~g} / \mathrm{L}$.

\section{CONCLUSÕES}

As condições operacionais para manutenção e crescimento do Clostridium acetobutylicum ATCC 4259 foram alcançadas, produzindo inóculos com boa viabilidade e respostas satisfatórias para o crescimento do micro-organismo utilizando glicerol como principal fonte de carbono em um processo descontínuo.

A análise estatística permitiu concluir que o ensaio ideal para o maior crescimento do Clostridium acetobutylicum ATCC 4259, dentro das condições experimentais, foi com a concentração de 30,0 g/L de glicerol P.A. e $2 \mathrm{~g} / \mathrm{L}$ de extrato de levedura no meio de cultura. 


\section{REFERÊNCIAS}

ANAND, P.; SAXENA, R. K.; MARWAH, R. G. A novel downstream process for 1,3propanediol from glycerol-based fermentation. Appl. Microbiol. Biotechnol., v. 90, n. 4, p. 1267-1276, 2011.

ASAD-UR-REHMAN; MATSUMURA, M.; NOMURA, N.; SATO, S. Growth and 1,3propanediol production on pre-treated sunflower oil biodiesel raw glycerol using a strict anaerobe Clostridium butyricum. Curr. Res. Bacteriol., v. 1, n. 1, p. 7-16, 2008.

CLOMBURG, J. M.; GONZALEZ, R. Anaerobic fermentation of glyrcerol: a plataform for renewable fuels and chemicals. Trends Biotecnol., v. 31, p. 20-28, 2013.

FERREIRA, F. G. D; LIMA, M. A. G. A.; VINHAS, G. M.; ALMEIDA, Y. M. B. Study of viability of 1,3-propanediol production by Clostridum acetobutylicum ATCC 4259. Can. J. Pur. Appl. Sci., v. 6, n. 3, p. 2057-2062, 2012.

FUKUDA, H.; KONDO, A.; TAMALAMPUDI, S. Bioenergy: sustainable fuels from biomass by yeast and fungal whole-cell biocatalysts. Biochem, Eng. J., v. 44, p. 2-12, 2009.

GÜNZEL B.; YONSEL, S.; DECKWER, W. D. Fermentative production of 1,3-propanediol from glycerol by Clostridium butyricum up to a scale of $2 \mathrm{~m}^{3}$. Appl. Microbiol., v. 36, p. 289-294, 1991.

KAUR, G.; SRIVASTAVA, A. K.; CHAND, S. Advances in biotechnological production of 1,3-propanediol. Biochem. Eng. J., v. 64, p.106-118, 2012.

LEONETI, A. B.; ARAGÃO-LEONETI, V.; DE OLIVEIRA, S. V. W. B. Glycerol as a byproduct of biodiesel production in Brazil: alternatives for the use of unrefined glycerol. Renew. Energ., v. 45, p. 138-145, 2012.

MOTA, C. J. A.; SILVA, C. X. A.; GONÇALVES, V. L. C. Gliceroquímica: novos produtos e processos a partir da glicerina de produção de Biodiesel. Quim. Nova, v. 32, p. 639$649,2009$.

PINTO, M. M. L. Obtención bioquímica de 1,3-propanodiol a partir de glicerina. Universidad de Valladolid, 2009.

YAZDANI, S. S.; GONZALEZ, R. Anaerobic fermentation of glycerol: a path economic viability for the biofuels industry. Curr. Opin. Biotech., v. 18, p. 213-219, 2007. 